\title{
Correction to: Rasch analysis of the Brain Injury Screening Tool (BIST) in mild traumatic brain injury
}

Nusratnaaz Shaikh ${ }^{1,2^{*}}$, Alice Theadom ${ }^{1,2}$, Richard Siegert ${ }^{2}$, Natalie Hardaker ${ }^{3,4}$, Doug King ${ }^{1,4,5}$ and Patria Hume Hum $^{1,4}$

\section{Correction to: BMC Neurol 21, 376 (2021)} https://doi.org/10.1186/s12883-021-02410-6

Following publication of the original article [1], the authors reported an error in Fig. 1 wherein the graph titles "Physical Emotional Symptoms Subscale; Vestibular Ocular Symptoms Subscale; Cognitive Symptom Subscale; BIST Total Scale) were not included in the image. The correct Fig. 1 is shown below.

The original article [1] has been updated.

\section{Author details}

${ }^{1}$ TBI Network, Auckland University of Technology, Auckland, New Zealand. ${ }^{2}$ School of Clinical Sciences, Auckland University of Technology, Auckland, New Zealand. ${ }^{3}$ Accident Compensation Corporation, Wellington, New Zealand. ${ }^{4}$ Sports Performance Research Institute New Zealand, Auckland University of Technology, Auckland, New Zealand. ${ }^{5}$ School of Science and Technology, University of New England, Armidale, NSW, Australia.

Published online: 10 November 2021

\section{Reference}

1. Shaikh $N$, Theadom A, Siegert R, et al. Rasch analysis of the Brain Injury

Screening Tool (BIST) in mild traumatic brain injury. BMC Neurol.

2021;21:376. https://doi.org/10.1186/s12883-021-02410-6.

\section{Publisher's Note}

Springer Nature remains neutral with regard to jurisdictional claims in published maps and institutional affiliations.

${ }^{2}$ School of Clinical Sciences, Auckland University of Technology, 


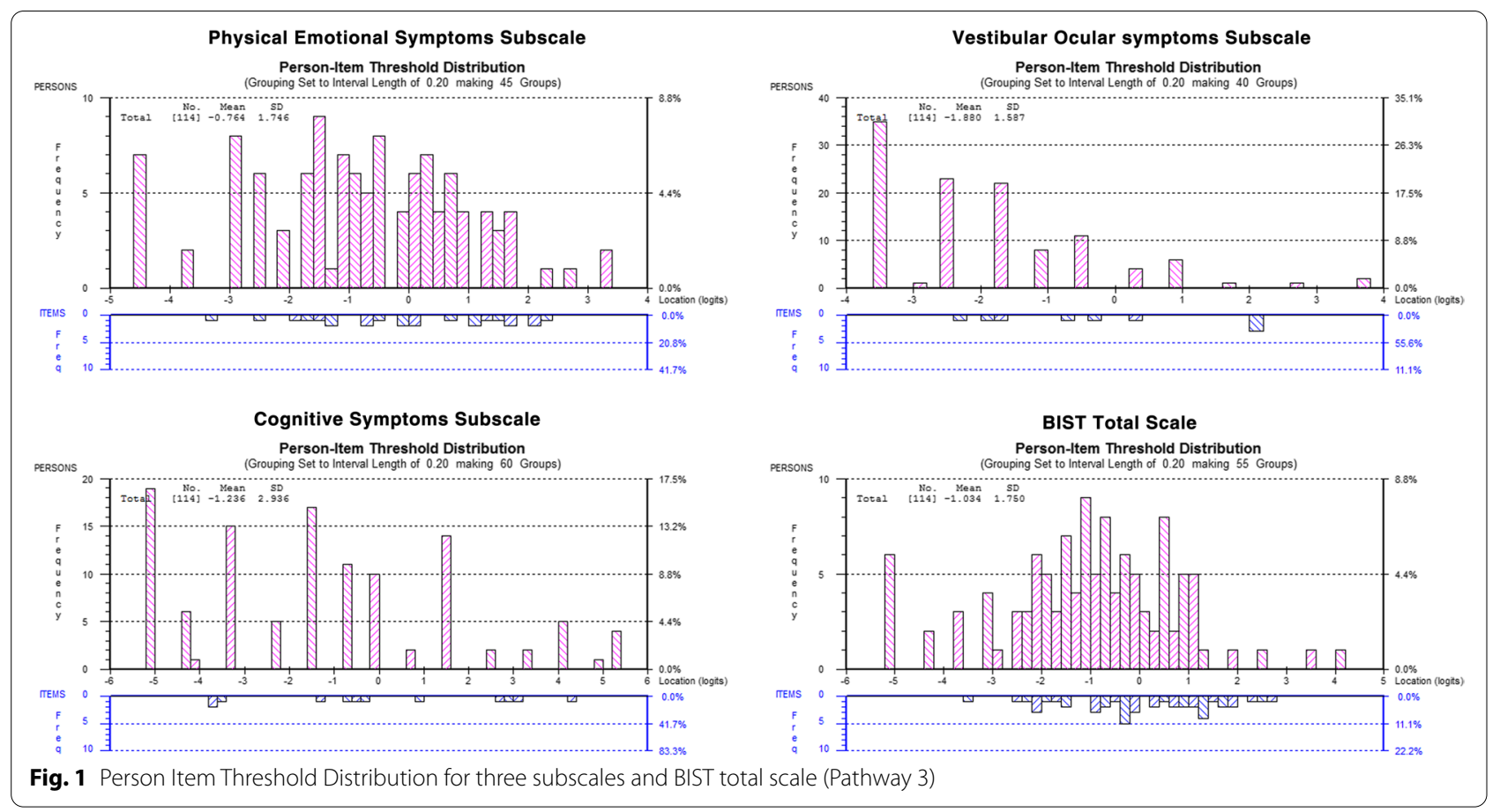

